\title{
Three-Phase PWM-Switched Autotransformer Voltage-Sag Compensator Based on Phase Angle Analysis
}

\author{
Muhamad Mansor ${ }^{\dagger}$ and Nasrudin Abd. Rahim* \\ $\dagger$ Dept. of Electrical Power Engineering, Universiti Tenaga Nasional, Selangor, Malaysia \\ ${ }^{*}$ UM Power Energy Dedicated Advanced Centre (UMPEDAC), University of Malaya, Kuala Lumpur, Malaysia
}

\begin{abstract}
Many voltage sag compensators have been introduced, including the traditional dynamic voltage restorer (DVR), which requires an energy storage device but is inadequate for compensating deep and long-duration voltage sags. The AC-AC sag compensators introduced next do not require a storage device and they are capable of compensating voltage sags. This type of compensator needs an AC-AC converter to regulate the output voltage. Presented in this paper is a three-phase PWM-switched autotransformer voltage sag compensator based on an AC-AC converter that uses a proposed detection technique and PWM voltage control as a controller. Its effectiveness and capability in instantly detecting and compensating voltage sags were verified via MATLAB/Simulink simulations and further investigated through a laboratory prototype developed with a TMS320F2812 DSP as the main controller.
\end{abstract}

Key Words: Peak detection, RMS detection, Voltage sag, Voltage sag compensator, Voltage sag detection

\section{INTRODUCTION}

Voltage sags cause expensive downtime, making them the focus of considerable research. They are a phenomenon of RMS voltage rapidly declining from $90 \%$ to $10 \%$ of the rated voltage, typically for 0.5 to 30 cycles [1]. Voltage sags are generally caused by lightning, accidental short circuits, loose connections, the starting of large motors (or air-conditioners), or abnormal use of AC mains [2]. Even short periods of voltage sag can cause irreversible damage to sensitive equipment and cause significant economic losses, owing to interruptions in industrial production [3].

Disturbances caused by voltage sags cause losses to not only production but also to utilities [4], [5]. There are increases in the demand for clean power as the use of microelectronic processors increases in various types of equipment such as computer terminals, programmable logic controllers, and diagnostic systems. These types of equipment are susceptible to disturbances in their supply voltage, and the widespread application of nonlinear electronic devices in power apparatuses and systems makes waveform distortions more significant.

One of the most popular topologies for voltage-sag compensators is the dynamic voltage restorer (DVR), which requires a voltage-source inverter (VSI) for the line-injection of series

Manuscript received Oct. 14, 2010; revised Aug. 26, 2011

Recommended for publication by Associate Editor Kyo-Beum Lee.

$\dagger$ Corresponding Author: Muhamadm@uniten.deu.my

TeX: +6-3-8928-7263, Fax: +6-3-7967-7637, Universiti Tenaga Nasional

* UM Power Energy Dedicated Advanced Center (UMPEDAC), University

of Malaya, Malaysia voltage, an injection transformer, and a dc link. One obvious disadvantage of this topology is its inability to compensate deep and long-duration voltage sags. Increasing its capability requires more energy storage devices, thereby increasing cost. Another consideration is environmental, since a battery is used as the energy storage device. Also, the voltage regulation of the dc link demands use of a separate ac-dc converter, which requires one more stage of power conversion, increasing size, cost, control complexity, and power losses [6].

Energy storage is unnecessary in AC-AC sag compensators. However, an AC-AC converter is needed to convert the dropped ac voltage to regulated ac voltage. The three-phase PWM-switched autotransformer voltage sag compensator presented here uses an AC-AC converter and a proposed voltage sag detection technique based on phase angle analysis. The proposed detection technique is able to detect and compensate voltage sags the moment they occur, even with the presence of harmonic content in the input voltage. A PWM voltage controller is chosen as the PWM control strategy.

\section{Voltage Sag Detection Techniques}

The speed of voltage-sag detection affects the dynamic performance of a compensator. Therefore, precise and fast voltage-sag detection is essential. Determined are the start, the end, and the severity, of voltage sags. Many techniques for voltage sag detection have been introduced include RMSValue Evaluation and Peak-Value Evaluation. 


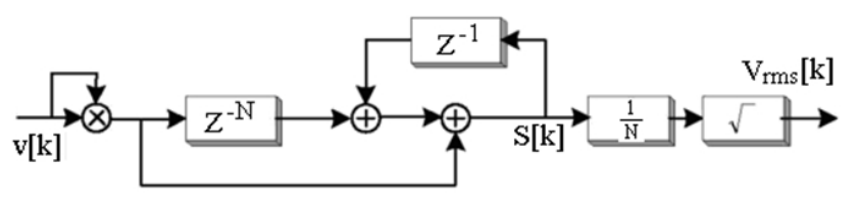

Fig. 1. RMS magnitude evaluation by using a moving window.

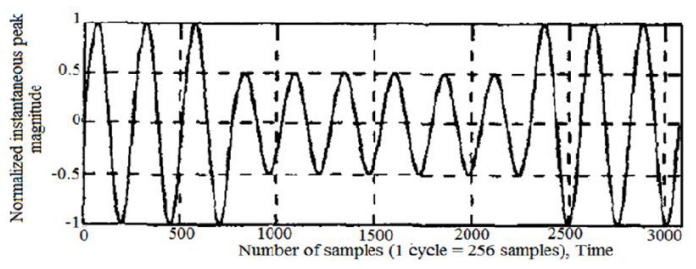

(a)

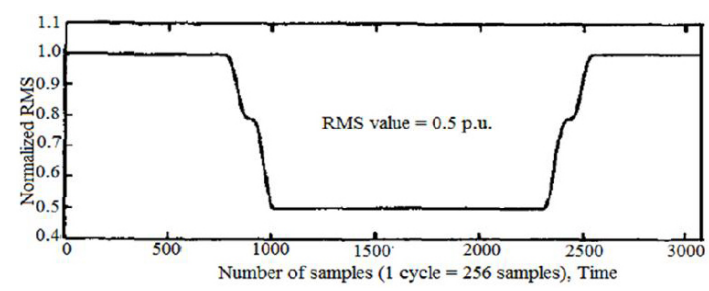

(b)

Fig. 2. (a) Ideal voltage-sag waveform (b) RMS of the sag waveform.

\section{A. RMS-Value Evaluation Method [2], [3], [8]}

When determining the amount of power available for equipment, AC voltage and current measurements are made. As a result, sag voltages are usually expressed in RMS terms. With an RMS computation, though, the information on phase and polarity is lost because the RMS uses only the absolute magnitude of a signal. In other words, an RMS value is based on the averaging of a previous cycle's sampled data. Therefore, it represents one cycle of a historical average value, not a momentary, or an instantaneous, reading.

The RMS values, continuously calculated for a moving window of input voltage samples, provide a convenient measure of magnitude evolution because they express a signal's energy content, assuming that the window contains $\mathrm{N}$ samples per cycle (or half cycle). The widely-used moving-window RMS value is calculated for digitally recorded data as follows. Each sampled component of one cycle of the waveform is squared and then the squares are summed. The square root of this sum is then calculated and a single value is plotted.

The basic idea is to follow the voltage magnitude changes as closely as possible during the disturbing event. Fig. 1 represents the RMS magnitude evaluation process through a moving window. The more RMS values are calculated, the more closely the disturbing event is represented. This is especially true of non-rectangular variations.

Fig. 2(a) shows an ideal voltage-sag, i.e., the transition occurs at the zero-crossing and there is no distortion during the sag. The sag has a 50\% depth and occurs for about a 6-cycle steady-state duration. Fig. 2(b) shows a RMS plot through the moving-window RMS computational technique based on Figure 2(a). The plot shows a one-cycle transition occurring before the 0.5 p.u. value is reached, and a one-cycle rise to

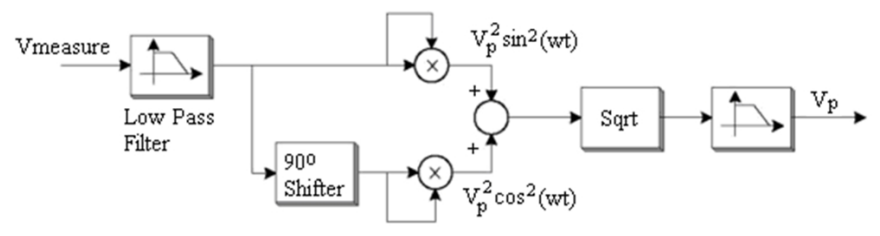

Fig. 3. Block diagram of the Peak detection technique

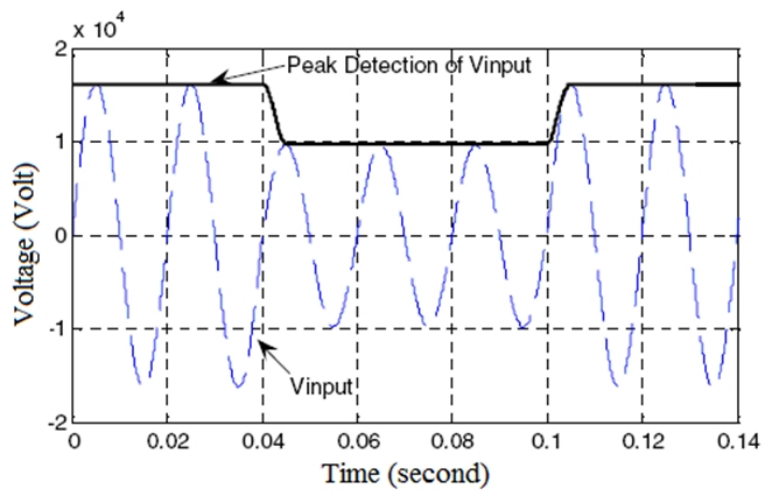

Fig. 4. Peak detection signal and Vinput versus time.

recovery. The slow transition is due to the fact that the moving window retains almost one cycle of historical information in the calculation.

\section{B. Peak-Value Evaluation Method [7]-[9]}

Fig. 3 shows a block diagram of a voltage measurement that uses peak detection.

$\mathrm{V}_{\text {measure }}$, as Fig. 3 shows, represents the single-phase lineto-neutral voltage. The voltage is shifted $90^{\circ}$, by using a $90^{\circ}$ shifter, to obtain a cosine value. Assuming that the line frequency is $50 \mathrm{~Hz}$, a $90^{\circ}$ shifted value can be obtained by either an analog circuit or by digital signal processing. Both voltage components are squared and summed to yield $V_{p}^{2}$. The peak value is then obtained by squaring the root of $V_{p}^{2}$. A significant advantage of the peak-value evaluation method over other methods is that it needs only single-phase values.

Fig. 4 shows the output value of the peak-detection block when compared to the input voltage. The comparison verifies the method's ability to detect the input signal's peak value in the shortest possible time. The detection took at least a quarter of a cycle.

\section{Development Of Control Scheme}

\section{A. Proposed detection technique}

The RMS-value evaluation and the peak-value evaluation take one cycle and at least a quarter of a cycle, respectively, to detect, and compensate a voltage sag. This is because the voltage controller used for the detection needs the voltage-sag information for at least a quarter of a cycle.

It is not necessary to retain the voltage-sag information, as the following proves: Fig. 5 represents the half cycle of a sinusoidal wave at normal voltage with a peak value of $100 \mathrm{~V}$, and voltage sags of $90 \% 80 \%, 70 \%, 60 \%$, and $50 \%$. L6 is a vertical line intersecting all of the sinusoidal waveforms 


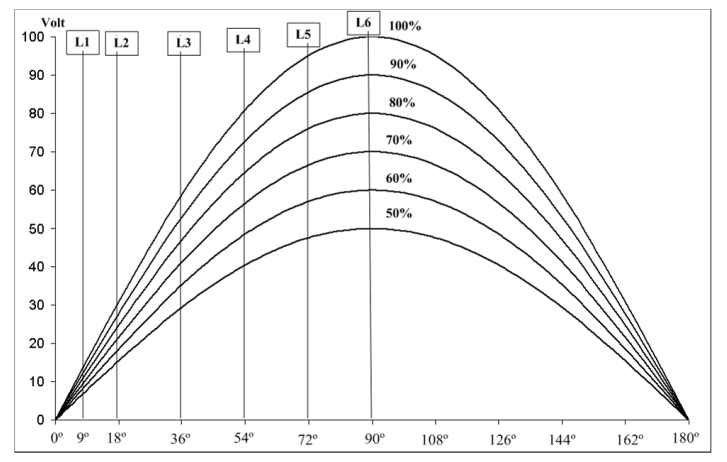

Fig. 5. Half cycle of a sinusoidal at various voltage amplitudes.

at $90^{\circ}$. The differences in the voltage amplitudes among the various voltage sags are clearly shown. L5, L4, L3, and L2 are vertical lines intersecting the sinusoidal waveform, at the phase angles $72^{\circ}, 54^{\circ}, 36^{\circ}$, and $18^{\circ}$, respectively. From L5 to L2, the differences in the voltage amplitudes for various voltage sags are also significant. The detection of voltage sags does not require a lot of time in confirming the occurrence, or nonoccurrence, of a sag. The different voltage amplitudes of the voltage sags are also significant at a $9^{\circ}$ phase angle. Therefore, information at $9^{\circ}$ is sufficient to indicate the presence of a voltage sag.

Based on this, a new voltage-sag detection technique based on phase angle analysis is introduced. It offers immediate detection and compensation of voltage sags. In other words, the new technique can detect and compensate sags the moment they occurs.

Determination of the voltage amplitude is done by using [10]:

$$
V(k)=V_{m} \sin (k w \Delta T)
$$

where $V(k)$ is the voltage at the sample $k, V_{m}$ is the peak voltage, $k$ is the sample in digital operation, $w$ is the fundamental frequency, and $\Delta T$ is the sampling time.

For example, if the sampling rate for one cycle of a sinusoidal waveform is $k=200$, the fundamental frequency is set to $50 \mathrm{~Hz}$ and $V_{m}=100 \mathrm{~V}$. Then sampling time is calculated as:

$$
\Delta T=\frac{20 \times 10^{-3}}{200}=100 \mu s .
$$

The magnitude of the normal voltage at the $5^{\text {th }}$ sample, equivalent to the $9^{\circ}$ phase angle, is calculated as follows:

$$
\begin{gathered}
V(5)=100 \sin [(5)(2 \pi)(50)(100 \mu)] \\
=15.64 V .
\end{gathered}
$$

If an allowable voltage drop is less than $10 \%$, therefore a voltage sag must be compensated if it drops to below $14.076 \mathrm{~V}$.

The magnitude of a $70 \%$ voltage sag at the $5^{\text {th }}$ sample $\left(9^{\circ}\right)$, where $V m=70 \mathrm{~V}$ is calculated as follows:

$$
\begin{gathered}
V(5)=70 \sin [(5)(2 \pi)(50)(100 \mu)] \\
=10.95 V .
\end{gathered}
$$

If (5) is compared with (4), the following is found:

$$
\frac{15.64-10.95}{15.64} \times 100 \%=30 \%
$$

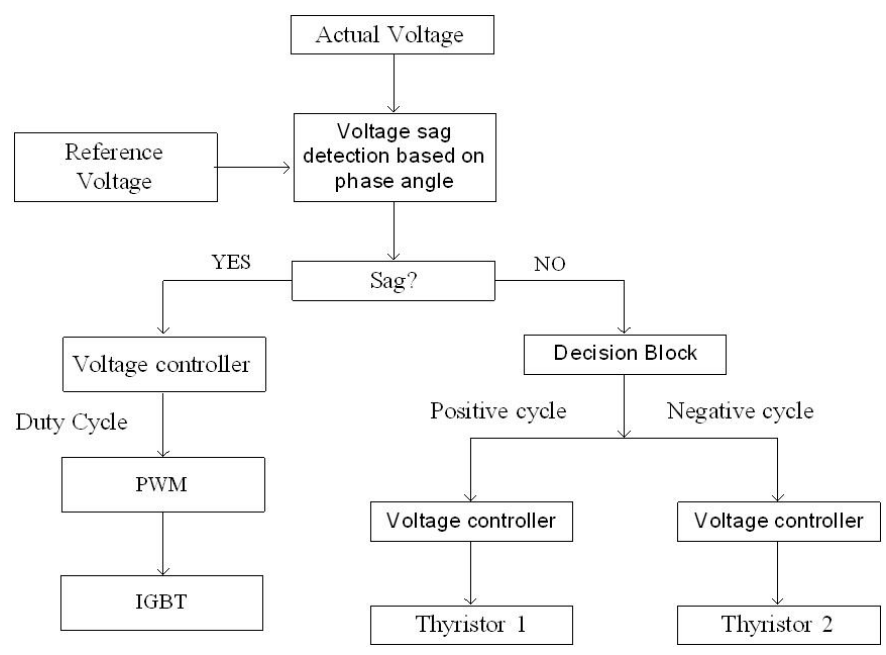

Fig. 6. Flowchart of the new voltage sag detection technique.

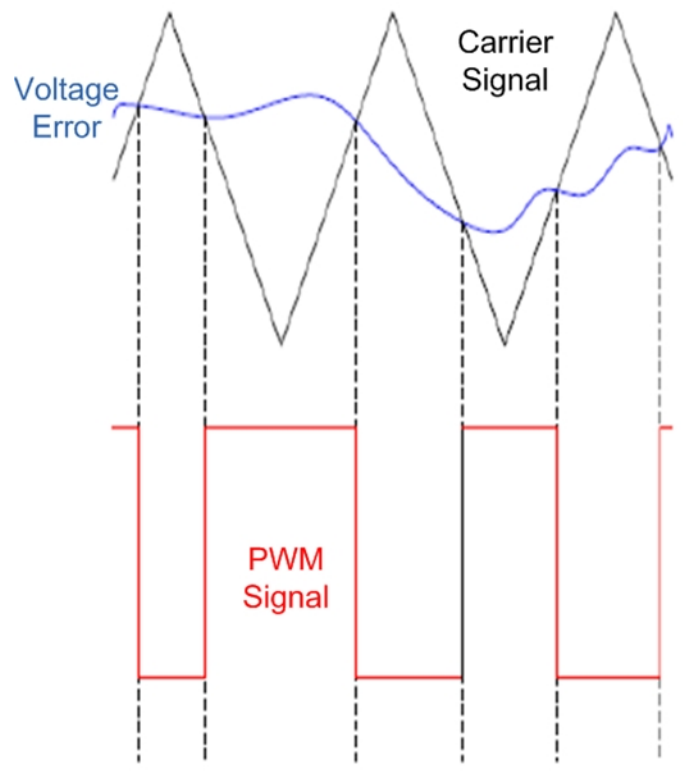

Fig. 7. PWM voltage control.

meaning a voltage drop to $30 \%$ of the rated voltage. This value is still the same as the percentage of voltage drop calculated at a $90^{\circ}$ phase angle.

This technique requires less computation when compared with other techniques. Fig. 6 shows the process of the new voltage sag detection technique. The actual voltage is compared with the reference voltage. This is done with voltage-sag detection based on phase-angle analysis, to determine whether a sag has occured or not. If there is no voltage sag, the decision block will split the waveform into positive and negative cycles. Gate signals for thyristor 1 and thyristor 2 are then generated and at the same time the IGBT is turned off. If a voltage sag is detected, the voltage controller generates duty cycles and PWM signals according to the sag severity. At this moment, thyristors 1 and 2 are turned off.

\section{B. PWM voltage control}

PWM voltage control is a preferred control technique as its implementation is easy. It is a carrier-based controller where the switching frequency is set and kept constant. Fig. 7 [11] 


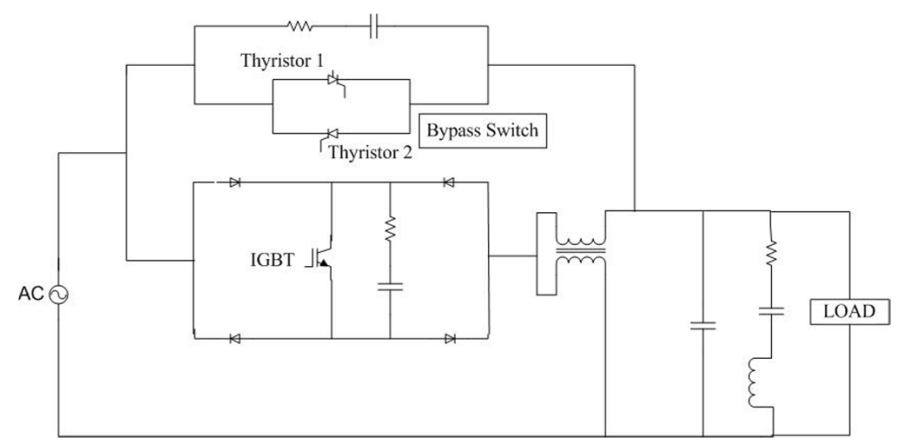

Fig. 8. Single-phase voltage-sag compensator.

presents the working principle of PWM voltage control. The frequency of a carrier signal is set according to the desired switching frequency. A comparison between the actual voltage and the reference voltage gives the voltage error, which is then compared with the carrier signal. The PWM signal is generated according to these conditions:

1) If voltage error > carrier: PWM is generated.

2) If voltage error $<$ carrier: PWM is not generated.

\section{Voltage Sag Compensator}

In this paper, the single-phase voltage sag compensator proposed in [10] is used as a reference when developing the three-phase voltage sag compensator; see Fig. 8. It comprises two thyristor bypass switches, one PWM insulated-gate bipolar transistor (IGBT) switch in bridge configuration, two output filters, and an autotransformer. The output filters comprise a notch filter and a capacitive low-pass filter, to reduce the harmonic components of the output voltage to less than 5\% THD as required in a power system. The compensator works for only a few seconds and remains in the off-state for most of its operation time. Its working principle can be described as follows; under normal conditions, the bypass switches (Thyristors 1 and 2) remain ON. If the sensing circuit detects more than a $10 \%$ voltage sag, the bypass switches are turned OFF by the voltage controller, which, at the same time, commands the IGBT to start PWM switching so that the output voltage is regulated and compensated back to normal voltage. Once the input voltage has no more sag or less than a $10 \%$ sag, the voltage controller commands the IGBT to turn OFF, turning the thyristors $\mathrm{ON}$. To suppress the peak voltage during turn OFF, an RC snubber is used at every switch, so that the current diverts to the snubber and the energy stored in the current path is dumped into the snubber capacitor every time the switches are turned OFF. Here, an autotransformer with a ratio of $\mathrm{N} 1: \mathrm{N} 2=1: 1$ is used to boost up to a $50 \%$ voltage sag.

Fig. 9 shows the three-phase voltage sag compensator configuration. Simulation and experimental results show the compensator producing the best output without filters. As a result, the low-pass filter and the notch filter were discarded from both the simulation and the experiment.

\section{Simulation}

The proposed three phase compensator was designed using MATLAB/Simulink simulation software. Fig. 10 shows the

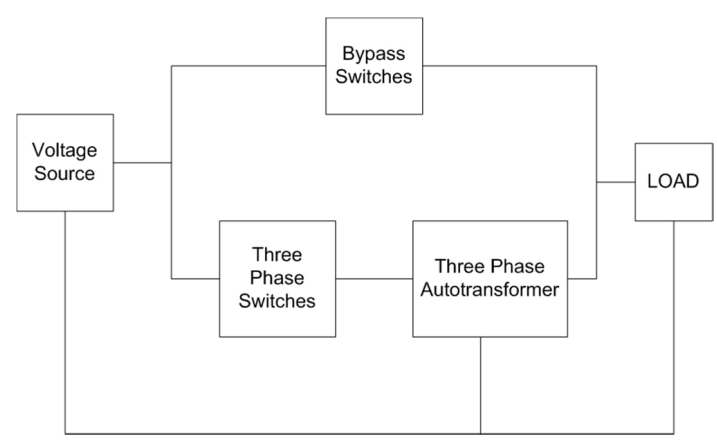

Fig. 9. Three-phase voltage-sag compensator without filters.

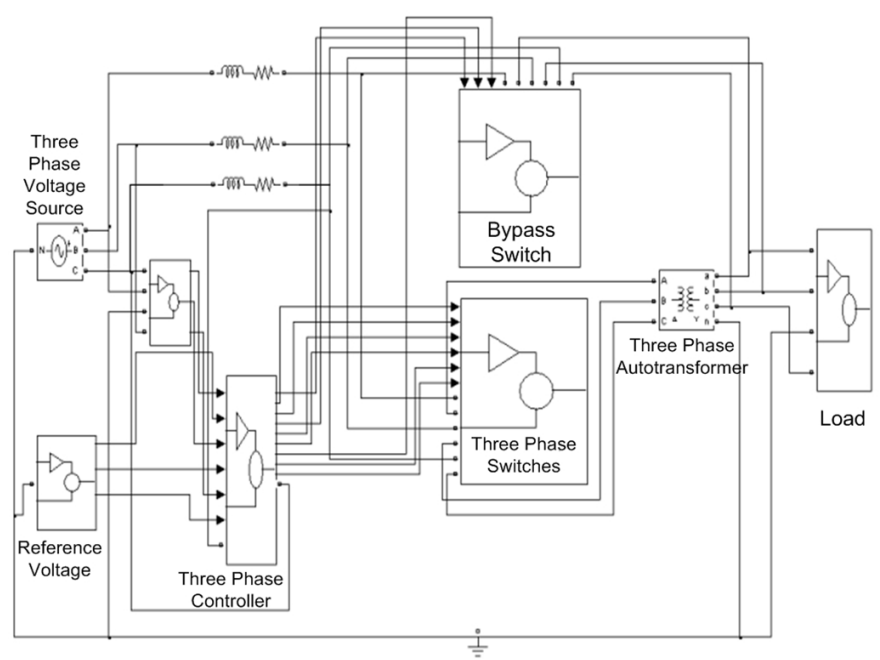

Fig. 10. Simulation block of the three-phase PWM-switch autotransformer voltage-sag compensator.

simulation block of the three phase compensator. The RCsnubber values used for the bypass switches were $\mathrm{R}=100 \Omega$ and $\mathrm{C}=1 \mathrm{nF}$, and for the IGBT they were $\mathrm{R}=7 \Omega$ and $\mathrm{C}=20 \mu \mathrm{F}$. As previously mentioned, the three-phase compensator differs from the single-phase compensator of [10] in terms of the filters. The IGBT switching frequency used for the PWM switch was $1.5 \mathrm{kHz}$. The simulated sag was $50 \%$ and it lasted 4 cycles (equalling 0.08s) for the balanced and unbalanced sag. Voltage sags at different phase angles were simulated to see the capability of the proposed detection technique in detecting sag occurrences.

Fig. 11 (a) shows an unbalanced sag in the three phase system where the sag occurs only on phase A. It dropped to $50 \%$ of the rated voltage at a $0^{\circ}$ phase angle. The sag was well regulated to the normal voltage immediately, as shown in Fig. 11(b).

Fig. 12 (a) shows another sag condition: a balanced threephase sag where the phase A voltage sags at $0^{\circ}$, the phase B voltage sags at $240^{\circ}$ and the phase $\mathrm{C}$ voltage sags at a $120^{\circ}$ phase angle. The gate signals are produced immediately according to the sag conditions, as shown in Fig. 12(b), while Fig. 12(c) presents the well regulated output voltage.

The gate signals are generated immediately once the detection circuit detects a voltage sag occurrence at any phase angle. The results obtained show that a voltage sag can be detected and compensated the moment it occurs. There is no delay and no difficulty in detecting a voltage sag and no disturbance in 

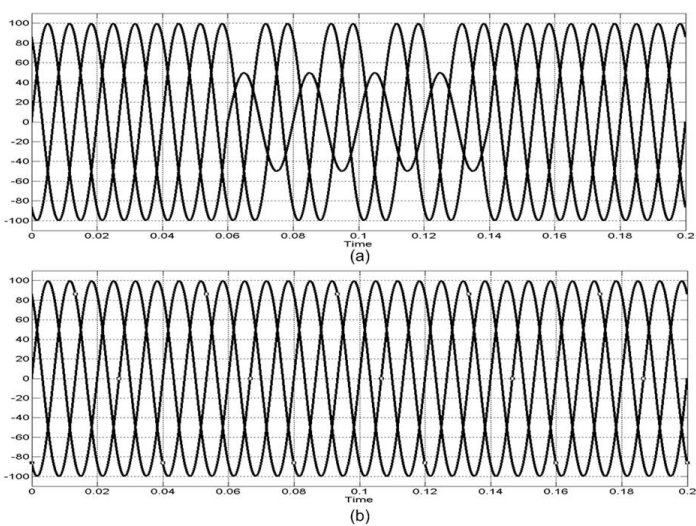

Fig. 11. Unbalanced voltage sag occurs at $0^{\circ}$ phase angle. (a) Sag occurs on phase A. (b) Compensated output voltage.

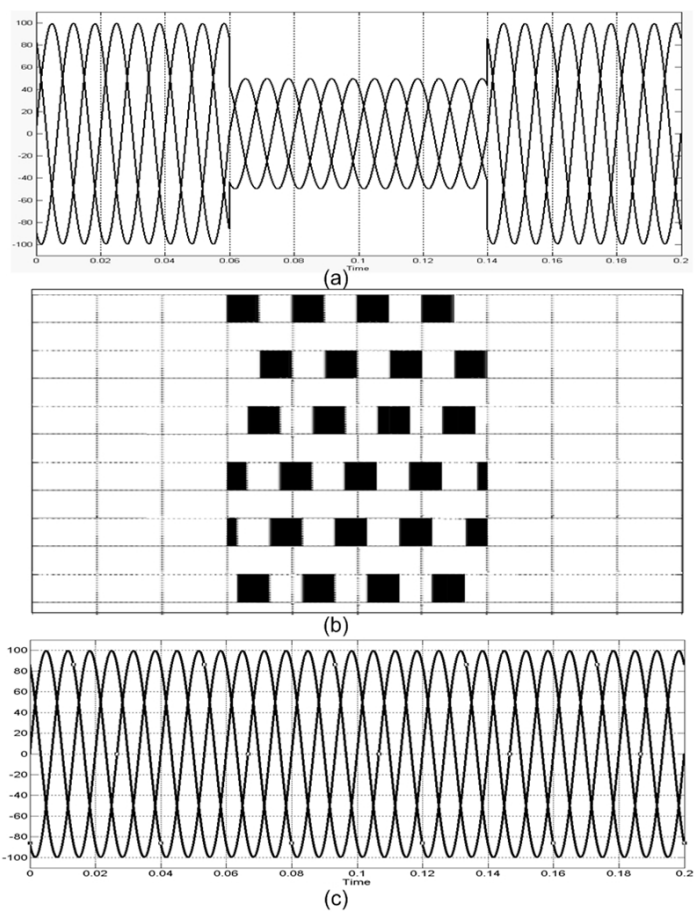

Fig. 12. Balanced three phase voltage sag. (a) Sagged voltage. (b) Gate signal for IGBT (c) Compensated output voltage.

the output voltage waveform.

\section{VALIDATION}

\section{A. Hardware development and software design}

To verify the results obtained from the simulation, a controller was designed and developed. A TMS320F2812 DSP was selected to implement the control algorithm as it has a 32bits CPU performing at $150 \mathrm{MHz}$. Other interesting features of the TMS320F2812 DSP are its 12-b ADC module handling 16 channels and two on-chip event manager peripherals providing a broad range of functions, particularly in control applications.

Fig. 13 shows the process flow of the proposed voltage sag detection controller. It consists of four stages; the detection circuit, the voltage sag detection, the voltage controller and the gate signal generator.

The detection circuit is in the form of hardware, which comprises a voltage sensor and zero crossing detectors, while the other stages are developed in the DSP programming. The

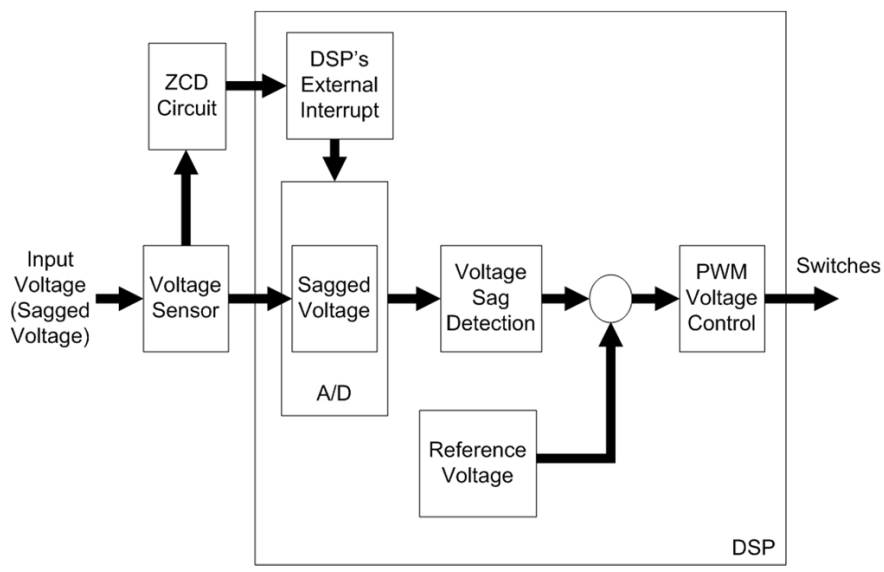

Fig. 13. DSP control block.

voltage sensor is developed to measure the input voltage or the sagged voltage and to feed the DSP with the voltage amplitude and the phase angle. The voltage sensor works together with a zero-crossing detector (ZCD). The ZCD is used for detecting the zero crossing of AC signals. The ZCD output initializes the starting time of the DSP's sampling operation by using the DSP external interrupt. The external interrupt is useful for system synchronization. The Analogue-Digital Module (A/D) will only start its operation once it receives permission from the external interrupt.

Conversion of analogue to digital is done in the A/D Module. The number of samples in one cycle captured from the input signals is determined by the sampling frequency set in the A/D Module. In digital control, the data is based on the sample time set through the controller [12]. This study uses 200 samples per cycle, for $50 \mathrm{~Hz}$ operation. Using equation (2), the sampling time is obtained as follows:

$$
\text { Sampling time }=\frac{20 m}{200}(s)=100 \mu s
$$

and,

$$
\text { Sampling frequency }=\frac{1}{100 \mu}=10 \mathrm{kHz}
$$

A $10 \mathrm{kHz}$ sampling frequency is set in the A/D module to obtain 200 samples of the input voltage magnitude in one cycle. A comparison between the sagged voltage and the reference voltage produces the voltage error which is later used to generate gate signals with the PWM voltage controller. The voltage sag is generated using a Programmable CHROMA AC Source.

\section{B. Experiment Results}

Fig. 14 (a) shows an unbalanced voltage sag in the three phase input voltage. The sag occurred at the beginning of cycle 4 (at the $0^{\circ}$ phase angle) and ended at cycle 8 . The results obtained from the experimental set up show that the singlephase sag was re-regulated well to normal voltage. This can be seen in Fig 14(b).

Fig. 15 (a) shows a balanced voltage sag where the input voltage dropped to $50 \%$ of the rated voltage. This sag condition is similar to that of the simulation where the phase A voltage sags at $0^{\circ}$, the phase B voltage sags at $240^{\circ}$ and the 


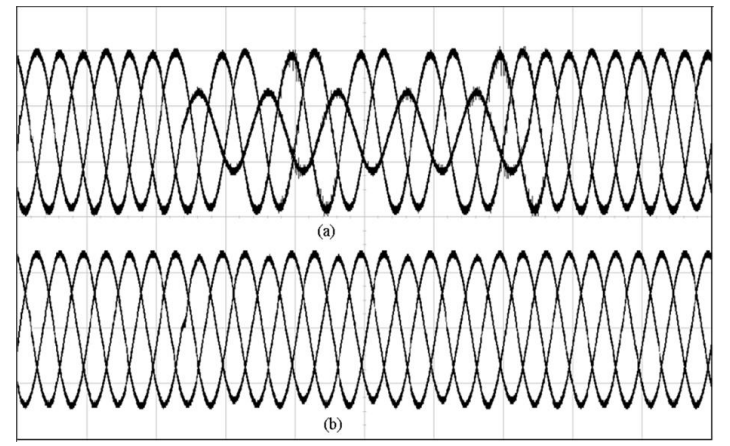

Fig. 14. (a) Single-phase voltage sag. (b) Regulated output voltage.

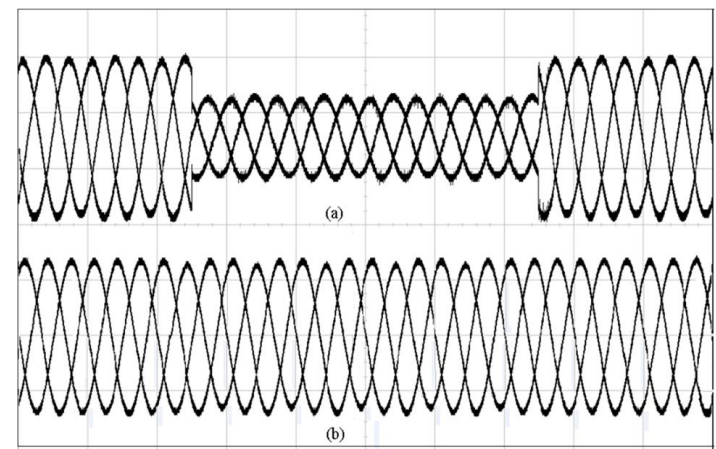

Fig. 15. (a) Three-phase voltage sag. (b) Regulated output voltage.

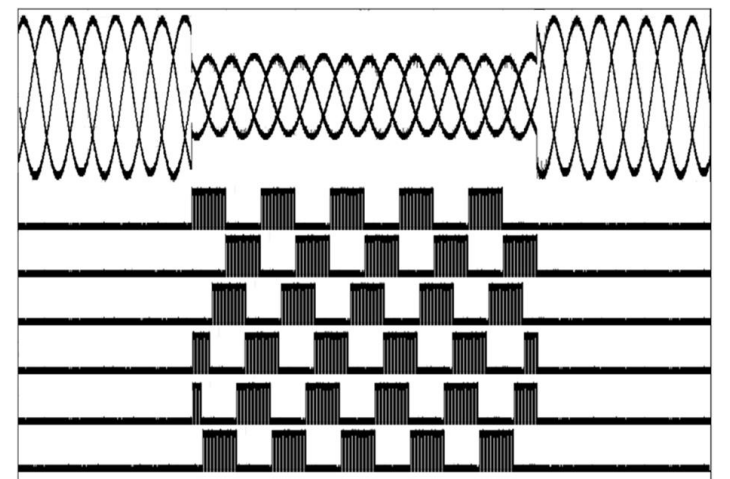

Fig. 16. Input voltage and gate signals for IGBT for three phase voltage sag.

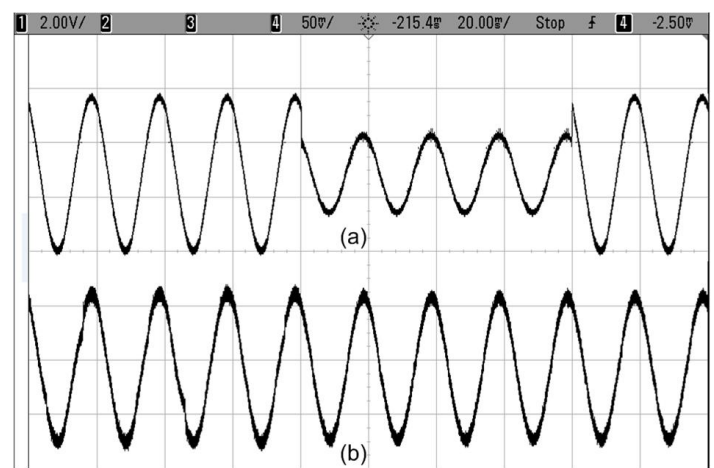

Fig. 17. (a) Voltage sag (50\%) vs. time at $120^{\circ}$ phase angle. (b) Output current waveform

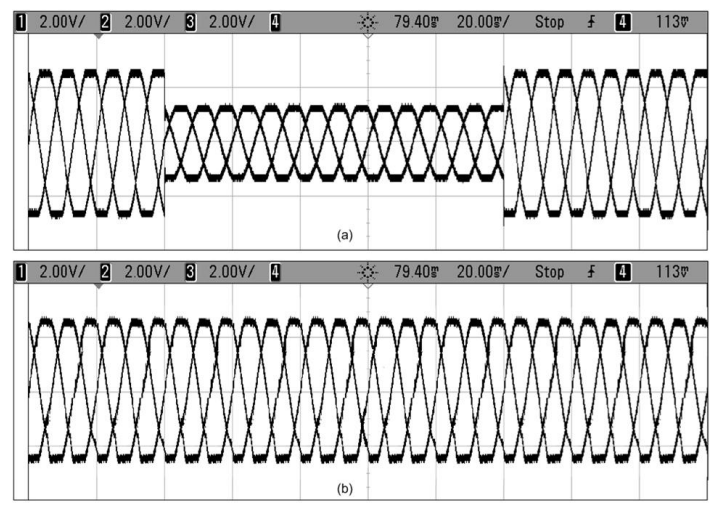

Fig. 18. (a) Balanced voltage sag (50\%) contains 5\% THD. (b) Compensated output voltage.

phase $\mathrm{C}$ voltage sags at a $120^{\circ}$ phase angle. As can bee seen in Fig. 15(b), the results obtained are similar to those from the simulation where a three phase sag was compensated back to a normal voltage without any waveform disturbances.

Fig. 16 shows the generated gate signals for the IGBTs in the three phase compensator for a balanced voltage sag event. It shows that the gate signals are generated the moment a sag occurs at any phase angle to drive the switches. These results are similar to those obtained in the simulation.

The output current is also observed during the sag event. Fig. 17(a) shows that the input voltage drops to $50 \%$ of the rated voltage at a $120^{\circ}$ phase angle, while Fig. 17(b) shows the output current.

Harmonic content in the input voltage is also presented to show the capability of the detection technique while working under the presence of harmonics. Fig. 18(a) shows an unbalanced sag where the three phase input voltage contains $5 \%$ THD. The output voltage is well regulated, as can be seen in Fig. 18(b).

\section{CONCLUSION}

A prototype of the three-phase PWM-switched autotransformer voltage sag compensator that uses the proposed detection technique is presented. Simulation results show that the compensator functions well in mitigating voltage sags. The design is verified by experiment results. The proposed voltage sag detection technique is able to detect and compensate voltage at any phase angle for both three phase balanced and unbalanced sags even in the presence of harmonics.

\section{REFERENCES}

[1] X. Xiao, Analysis and Control of Power Quality, Beijing: Cina Electronic Power Press, pp. 124-128, 2006.

[2] Y.-S. Lee, H.-C. So, M. Chow, "Design of ac voltage compensators," IPEMC, pp. 2587-2590, 2009.

[3] S. M. Deckmann and A. A. Ferreira, "About voltage sags and swell analysis," IEEE International conference on harmonics and quality of power, pp. 144-148, 2002.

[4] L. Guasch, F. Coŕcoles, and J. Pedra, "Effects of symmetrical and unsymmetrical voltage sags on induction machines," IEEE Trans. Power Deliv., Vol. 19, No. 2, pp. 774-782, Apr. 2004.

[5] J. Pedra, L. Saïnz, F. Coŕcoles, and L. Guasch, "Symmetrical and unsymmetrical voltage sag effects on three-phase transformers," IEEE Trans. Power Deliv., Vol. 20, No. 2, pp. 1683-1691, Apr. 2005.

[6] S. Subramaniam, M. K. Mishra, "Interphase ac-ac topology for voltage sag supporter," IEEE Trans. Power Electron., Vol. 25, No. 2, pp. 514518, Feb. 2010. 
[7] C. Hui-Yung, J. Hurng-Liahug, and H. Chieng-Lien, "Transient response of a peak voltage detector for sinuaoidal signals," IEEE Trans. On Industrial Electronics, Vol. 39, No. 1, pp. 74-79, Feb. 1992.

[8] K. Ding, K. W. E. Cheng, X. D. Xue, and B. P. Divakar, "A novel detection method for voltage sags," $2^{\text {nd }}$ International Conference on Power Electronics Systems and Application, pp. 250-288, 2006.

[9] A. A. Koolaiyan, A. Sheikhoeslami, and R. A. Kordkheili, "A voltage sag compensation utilizing autotransformer switched by hysteresis voltage control," $5^{\text {th }}$ International Conference on Electrical and Computer Engineering, Dhaka Bangladesh, pp. 545- 550, 2008.

[10] D. M. Lee, T. G. Habetler, R. G. Harley, T. L. Keister, J. R. Rostron, "A voltage sag supporter utilizing a pwm-switched autotransformer," IEEE Trans. Power Electron., Vol. 22, No. 2, pp. 626-635, Mar. 2007.

[11] B. K. Bose, Power Electronics and Variable Frequency Drives, Wiley, John \& Sons, 1996.

[12] M. A. M. Radzi and N. A. Rahim, "Neural network and bandless hysteresis approach to control switched capacitor active power filter for reduction of harmonics," IEEE Trans. Ind. Electron., Vol. 56, No. 5, pp. 1477-1484, May 2009.

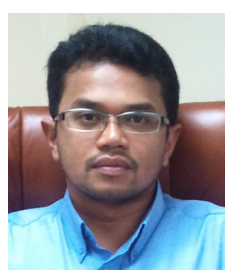

Muhamad Mansor was born in Johor, Malaysia in 1977. He received his B.Eng. (with Honours) from the Universiti Teknologi Malaysia and his M.Eng. in Electrical Power from the Universiti Tenaga Nasional, Malaysia, in 2000 and 2006, respectively. He is currently working toward his Ph.D. at the UM Power Energy Dedicated Advanced Centre (UMPEDAC), University of Malaya, Kuala Lumpur, Malaysia. He is currently a Lecturer in the Department of Electrical Power, Universiti Tenaga Nasional, Malaysia. Mr. Muhamad is a member of the IEEE and the Board of Engineers, Malaysia.

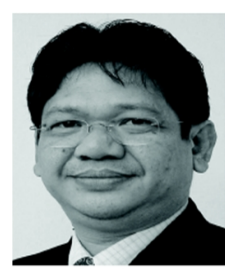

Nasrudin Abd. Rahim (M'89-SM'08) was born in Johor, Malaysia, in 1960. He received his B.S. (with Honours) and his M.S. from the University of Strathclyde, Glasgow, U.K., and his Ph.D. in 1995, from Heriot-Watt University, Edinburgh, U.K. He is currently a Professor in the Department of Electrical Engineering, University of Malaya, Kuala Lumpur, Malaysia and the Director of the UM Power Energy Dedicated Advanced Centre (UMPEDAC). Dr. Rahim is a Fellow of the Institution of Engineering and Technology, U.K. and a Chartered Engineer $\mathrm{He}$ is also Chairman of the Working Group WG-8, covering reluctance motors, of the IEEE Motor Subcommittee under the IEEE Power Engineering Society/Electric Machinery Committee. His research interests include power electronics, real-time control systems, and electrical drives. 